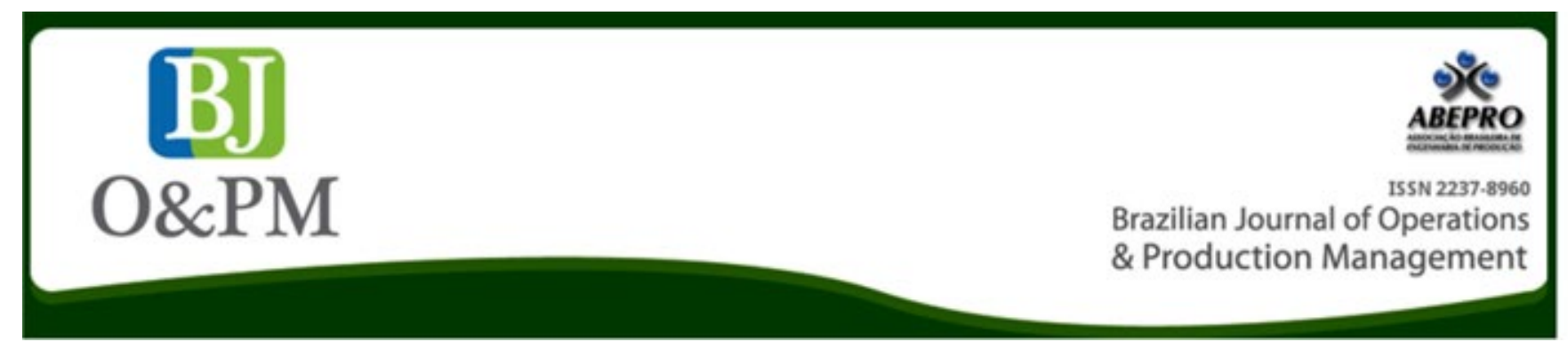

\title{
A STATE OF ART ON ECONOMIC PRODUCTION QUANTITY MODELS
}

\author{
Atul B. Borade ${ }^{1}$, Pankaj S. Ardak ${ }^{2}$
}

1 Department of Mechanical Engineering, Jawaharlal Darda Institute of Engineering \& Technology

2 Department of Mechanical Engineering, P.R. Pote College of Engineering \& Management

\begin{abstract}
Economic ordering quantity is a commonly accepted inventory management model. Its variant economic production quantity (EPQ) model is also a widely researched inventory model. The number of researchers had developed the EPQ model by considering different parameters, such as shortage, backorder, setup cost, deterioration, constant or linear or power form of the demand, rework, scrap, inspection, machine breakdown, etc. The objective of this paper is to review the literature, identify the gap in literature, develop and expand the knowledge base regarding EPQ models. This state of art paper would act as a guideline for researchers. The wide spectrum of the subject provides interesting future research problems.
\end{abstract}

Keywords: Inventory management; Economic Production Quantity; Review. 
Brazilian Journal of Operations \& Production Management

Volume 14, Número 1, 2017, pp. 183-186

DOI: 10.14488/BJOPM.2017.v14.n2.a5

\section{INTRODUCTION}

Every organization deals with inventory and adopts suitable inventory management system. Inventory management involves material, human, physical and information resources. The process is a little complex and evolves continuously. Investment in inventories represents a considerable amount of money (Jinn-Tsair et al., 2005). Unless inventories are controlled, they are unreliable, inefficient and costly. Cash invested in inventories could be used for other purposes, such as paying debts or making capital investments. Effective inventory management helps organizations to save money. Inventory management must determine how much and when to order/produce each item purchased/manufactured by the organization (Mehdi et al., 2011). The machine failure, state of the production process, product quality, and inflation has the important role in the determination of the optimal inventory replenishment policy (Feng-Tsung et al., 2010; Kuo-Lung, 2007; Singh et Singh, 2012). It is observed that, when items are produced internally instead of being obtained from the outside, the EPQ model is often used to determine the optimal production lot size in order to minimize the total inventory and production cost (Shamsi et al., 2009). A considerable amount of the research has been carried out to enhance the classical EOQ $E P Q$ model. The classical EPQ model has been used in industry and research for a long time. The objective of this paper is to review the related literature and find out the research gap and future scope for research.

\section{LITERATURE REVIEW.}

If we analyze the product life cycle, it is observed that the demand rate and the unit cost of product is stable only in the maturity stage of the product. However, in today era of cutthroat competition and shorter product life cycle, the demand rate as well as unit purchase cost of the product cannot remains fixed or constant.

Jinn-Tsair et al. (2005) developed the EPQ model and found it suitable for all time horizons of the product life cycle. It was assumed that demand rate and production cost both are positive and fluctuating with time. The model was developed for the firm which adopted vendor managed inventory. The total cost was found to be convex function of number of replenishments. The model showed the influence of demand and purchase cost over the length of the production run time and EPQ. The rate of production was constant for the model. However it could be extended by assuming the time varying production rate, deterioration rate, shortages and quantity discount. During production, run machine may have random failures and production bottlenecks. Defective machine may produce defective items. All abovementioned factors influences $E P Q$, hence there must be an appropriate preventive maintenance policy.
Mehdi et al. (2012) analyzed an EPQ model by considering preventive maintenance, work in process inventory and shortages. After machining, all products were inspected to determine the perfect and imperfect items. If imperfect items were present, then they were divided into reworkable and non-reworkable items. Reworkable items were machined again to be converted into perfect items. The model was developed to select the preventive maintenance policy. The model could be further improved by considering other policies of the maintenance, such as corrective maintenance, emergency maintenance, etc. The random machine failure seems to be inevitable in most of the real manufacturing environment. Thus, for most of the production planner it becomes a critical task, to effectively control the disruption caused by the random breakdown in order to minimize the overall production cost. Hence, the determination of the optimal replenishment policy for the production system subject to machine failure has received the attention from researchers. Feng-Tsung et al. (2010) considers imperfect quality EPQ model to obtain the optimal inventory replenishment by considering backorder, rework, and random machine failure. Uniformly distributed defective rate and poison distributed breakdown rate was assumed for the study. Due to randomness of defective, scrap, and breakdown rate, renewal reward theorem with variable cycle length and use of integration is used to deal with the random breakdown in terms of stock piling time. The model can be extended to investigate the effect of the random machine failure in backorder refilling time.

It is observed that the quality of the product usually depends on the production process. Several authors developed various models to study the effect of imperfect process on the lot size. In most of the studies, set up cost is treated as a constant. But in practice the set up cost could be reduced through various ways. Kuo-Lung (2007) found that set up cost reduction and quality improvement has a great effect on production system efficiency. The relationship between the cost and capital investment was described by the logarithmic investment function. It was proved that reduction in set up leads to a reduction in optimal production run length, whereas investment in process quality improvement leads to increase in terms of optimal production run length. It was also found that inflation influences the inventory policy to any significant level. Singh et Singh (2012) studied power form stock dependent demand for $E P Q$ model. A genetic algorithm with varying population size was used to solve the model. It was found that the algorithm was efficient to solve the EPQ model. Interestingly, it is observed that profit increases with increase in demand. By assuming that the constant fraction of the on-hand inventory deteriorates and that the demand rate depends on the amount of the stock level, the EPQ model was developed. Newton's method was employed for cost optimization. It was concluded that, with increase in pro- 
duction, maximum inventory level and total cost increases. The EPQ model showed that the optimum lot size would generate minimum production cost if all produced items are of perfect quality and with no shortage (Jain, 2007).

The production of imperfect quality items, rework, and backlogging and inspection error could be integrated into a single EPQ model. Shamsi et al. (2009) considered the imperfect items to be sold as a single batch at a lower price through $100 \%$ inspection process. The finding of this study showed that the changes in net batch quantity could satisfy the demand and the total cost (Shamsi et al., 2009). Some researchers adopt novel approach in their study. Chen (2009) deployed Taguchis' symmetric quadratic quality loss function for evaluating the product quality. It was observed that the process standard deviation, the demand rate and quality loss coefficient has a major effect on the expected total cost per unit time. The model could be extended by considering other parameters, such as inspection error, manufacturing cost, and defective cost. Jaggi et Mittal (2011) developed a model that helps the retailer to determine the ordering policy. Initially the demand and production rate could be variable; however, in the later stage both become constant. It is observed that, in such situation, demand could be increased by offering discount on the selling price and by reducing the deterioration.

Garg et al. (2012) determined optimal discount to be given on unit-selling price when deterioration is considered. It was assumed that the deterioration is non-instantaneous, non-repairable and non-replaceable. The developed model was found suitable for new automobiles, mobile phones, fashionable goods, etc. However, in practice, the production system may be disrupted due to uncertainty and unplanned events and this may affect the demand and the margins.

Khedlekar (2012) developed the EPQ model to study the variation in demand with the disrupted production system. It was assumed that during production disruption, if shortage occurs, then it could be ordered from the spot market. Exponential demand was considered for the study. It was found that, if the demand increases, the management needs to order more from the spot market and, if demand rate decreases, it needs to stop the production before the planned time. Mishra et Singh (2011) attempted the EOQ model with uniform replenishment rate, a power form of demand and cubic deterioration. An algorithm was developed to find the optimal solution of the problem. The program in $\mathrm{C}^{++}$was written to compute the total optimal cost of the inventory model. It was observed that, as the replenishment rate, the set up cost per cycle, and the holding cost per cycle increases, the total optimal average cost of the inventory cycle increases. In practice, many customers have to wait for backlogged items during the shortage period. The longer the waiting time, the smaller is the backlogging rate. In such situation, taking backlogging rate into account becomes a necessity. Bansal et Ahalawat (2012) considered exponential demand under inflation. Two warehouse inventory problems were considered for the study. The developed model assists the decision maker to decide whether to rent the warehouse or not. Perfect or imperfect production system, perishable or nonperishable items are selected and the classical optimization technique or algebraic methods or differential calculus methods were applied to derive the model.

In some research studied, the arithmetic geometric means inequality and Cauchy Bunyakovsky Schwarz inequality was used to derive the optimal lot size and the optimal backorder level for EOQ and EPQ models with backorder (Cárdenas-Barron, 2001; 2010). The economic production quantity model could be efficiently solved by the use of algebraic methods. In the model developed by Lan et al. (2007), stochastic lead time and finite range, shortages and backlogs were considered to get the deeper insight of the problem. Teng et al. (2005) proposed an algorithm to determine the optimal replenishment cycle time and ordering quantity. The EOQ model from the previous research was extended, considering a deteriorating item and a non-zero ending inventory. It was observed that an increase in selling price results could increase optimal length of ordering cycle, optimal inventory level and maximum total profit per unit time. Similarly, the optimal length of ordering cycle, optimal ordering quantity and maximum total profit per unit time could decrease with increase in the deteriorating rate. Chang (2004) proposed the EPQ model by integrating deteriorated items with preventive maintenance and random machine breakdown. The corrective and preventive maintenance time was assumed to be stochastic and the unfilled demand was considered as lost sales. Meanwhile Widyadana et Wee (2012) developed the EPQ model for imperfect items with shortage and screening constraints. The renewal reward theorem was applied to calculate the total expected profit per unit time.

\section{CONCLUSIONS}

A literature review reveals that there are a number of EPQ models developed by various researchers. Little evidence is found in the literature that developed EPQ model for the organization adopting VMI. VMI could bring significant cost savings; therefore, research has a scope to develop EOQ/ EPQ models for VMI system. Furthermore, the combination of numerous parameters is possible for developing a new EPQ model. Various algebraic techniques, such as Newton's method, Taylor's series approximation, Dynamic programming, and Renewal reward theorem had been used for optimization; therefore, there is still scope for artificial intelligence methods. Further research could be carried out by considering machine breakdown in production period, during backorder refilling time with linear or power form 
Brazilian Journal of Operations \& Production Management

Volume 14, Número 1, 2017, pp. 183-186

DOI: 10.14488/BJOPM.2017.v14.n2.a5 of demand and demand as a function of the selling price of the stock.

\section{REFERENCES}

Bansal, K. K. et Ahalawat, N. (2012) Integrated Inventory Models for Decaying Items with Exponential Demand under Inflation. International Journal of Soft Computing and Engineering July, Vol. 2, No. 3.

Cárdenas-Barron, L. E. (2001) The economic production quantity (EPQ) with shortage derived algebraically. International Journal Production Economic, Vol. 70, pp. 289-292.

Cárdenas-Barron, L. E. (2010) An easy method to derive EOQ and EPQ inventory models with backorders. Computers and Mathematics with Application, Vol. 59, pp. 948-952.

Chang, H. C. (2004) A Note on the EPQ Model with Shortages and Variable Lead Time. Information and Management Sciences, Vol. 15, No.1, pp 61-67.

Chen, C. (2009) The Modified Economic Manufacturing Quantity Model for Product with Quality Loss Function. Tamkang Journal of Science and Engineering, Vol. 12, No. 2, pp. 109-112.

Feng-Tsung, C., Huei-Hsin, C., Singa, W. C. (2010) Economic production quantity model with backordering, rework and machine failure taking place in stock pilling time. Information Science and applications, Vol. 7, No. 4.

Garg, G., Vaish, B., Gupta, S. (2012) An Economic Production Lot Size Model with Price Discounting for Non-Instantaneous Deteriorating Items with Ramp-Type Production and Demand Rates. Int. J. Contemp. Math. Sciences, Vol. 7, No. 11, pp. 531-554.

Jaggi, C. K et Mittal, M. (2011) Economic order quantity model for deteriorating items with imperfect quality. Revista Investigacion Operacional, Vol. 32, No. 2, pp. 107-113.

Jain, M., Rathore, S. (2007) Economic production quantity models with Shortage, price and stock-dependent Demand for deteriorating items. IJE Transactions, Vol. 20, No. 2, pp. 159-166.

Jinn-Tsair, T., Liang-Yuh, O., Chun-Tao, C. (2005) Deterministic economic production quantity model with time-varying demand and cost, Applied Mathematical Modelling, Vol. 29, pp. 987-1003.
Khedlekar, U. K. (2012) A disruption production model with exponential demand. International Journal of Industrial Engineering Computations, Vol. 3, pp. 607-616.

Kuo-Lung, H. (2007) An EPQ model with set up cost and process quality as function of capital expenditure. Applied mathematical modeling, Vol. 31, pp. 10-17.

Lan, C., Yu, Y., Lin, R. H. et al (2007) A Note on the Improved Algebraic Method for the EPQ Model with Stochastic Lead Time. Information and Management Sciences, Vol. 18, No.1, pp. 91-96.

Mehdi, A., Seyed, M. S., Seyed, A., Nilipour, T. (2011) A New EPQ Model with Considering Preventive Maintenance, Imperfect Product, Shortage and Work in Process Inventory. Interdisciplinary journal of contemporary research in business, Vol.3, No 8.

Mishra, S. S. et Singh P.K. (2011) A Computational Approach to EOQ Model with Power form Stock Dependent Demand and Cubic Deterioration. American Journal of Operation Research, Vol. 1, No. 1, pp. 5-13.

Shamsi, R., Haji, A., Nourbakhsh, F. (2009) Economic Production Quantity in Reworkable Production Systems with Inspection Errors, Scraps and Backlogging. Journal of Industrial and Systems Engineering, Vol. 3, No. 3, pp 170-188.

Singh, C., Singh, S. R. (2012) An EPQ Model with Power form Stock Dependent Demand under Inflationary Environment using Genetic Algorithm. International Journal of Computer Application June 2012, Vol.48, No.1.

Teng, J., Ouyang, L., Cheng, M. (2005) An EOQ Model for Deteriorating Items with Power Form Stock-Dependent Demand. Information and Management Sciences, Vol. 16, No.1, pp. 1-16.

Widyadana, G. A. et Wee, H. M. (2009) Economic Production Quantity (EPQ) deteriorating inventory model with machine breakdown and stochastic repair time. Industrial Engineering and Engineering Management, available from: http://ieeexplore.ieee.org/document/5373279/?reload=true (Access: 10 Dec. 2014)

Widyadana, G. A. et Wee, H. M. (2012) An economic production quantity for deteriorating items with preventive maintenance policy and random machine breakdown. International Journal of System Science, Vol. 43, No. 1870-1882. 